\title{
PID Control of Elderly Assistant and Walking Assistant Robot
}

\author{
Odekhe Randolph Osivue ${ }^{1}$, Xiaodong Zhang ${ }^{1,2}$, Xiaoqi $\mathrm{Mu}^{1}$ and Hamza Khaled Kadry ${ }^{1}$ \\ ${ }^{1}$ School of Mechanical Engineering, Xi'an Jiaotong University, Xi'an, 710049, China \\ ${ }^{2}$ Key Laboratory of Education Ministry for Modern Design and Rotor-Bearing System, Xi'an Jiaotong University, Xi'an \\ 710049, Xi'an, China
}

\begin{abstract}
In this paper, a PID controller is applied to control the speed and direction of an elderly-assistant and walking-assistant robot (EWR) by controlling the speed and direction of two $12 \mathrm{~V}$ brushless DC (BLDC) motor driving two front hub wheel of the EWR. C code for the PID controller run on ATMega16 microcontroller. The parameter of a standard PID controller for the BLDC motor speed and direction control system under the investigation is tuned and fixed throughout the control. The result of the experiment on the real plant demonstrates that the PID controller is a good choice to suppress the oscillation due to the systems and sensors nonlinearity.
\end{abstract}

Keywords-BLDC motor; PID controller; tactile slip sensor;elderly-assistant walking-assistant robot

\section{INTRODUCTION}

In this paper, a PID controller design for an elderlyassistant and walking-assistant robot (EWR) driven by two $12 \mathrm{~V}$ brushless dc (BLDC) motor is presented.

BLDC motor speed and direction system are usually controlled by proportional integral derivative (PID) control algorithms with PID coefficients tuned for optimizing operation and performance [1]. The objective of a PID controller in a speed and direction control system is to maintain a speed set point at a given value and be able to accept new set point values dynamically. Modern speed control environments require controllers that are able to cope with parameter variations and system uncertainties [1].

To implement a PID controller, the proportional gain $K_{P}$, the integral gain $K_{I}$ and the derivative gain $K_{D}$ must be determined carefully, controlling the BLDC motor without using the PID controller will give some oscillation in the signal and because the system is nonlinear, controlling by function is the best way to control the nonlinear systems and PID controller is the best choice to achieve this task [1]. Two BLDC motors drive the two front wheels in the forward, backward and differential directions respectively. The motor drive system of the EWR is applied to overcome the load resistance and this is achieved by controlling the speed. The more motor speed the less torque the lesser the motor speed the higher the torque [1]. Controlling speed is done by using PWM (Pulse Width Modulation) all of this written in C code using avr studio and loaded to The ATMega 16 microcontroller.

\section{ELDERLy AsSistant AND WALKING AsSistant RoBOT DESCRIPTION}

EWR (Elderly-Assistant and Walking-Assistant Robot) as shown in Figure 1 is a research project of the Key Laboratory of Education Ministry for Modern Design and Rotor Bearing

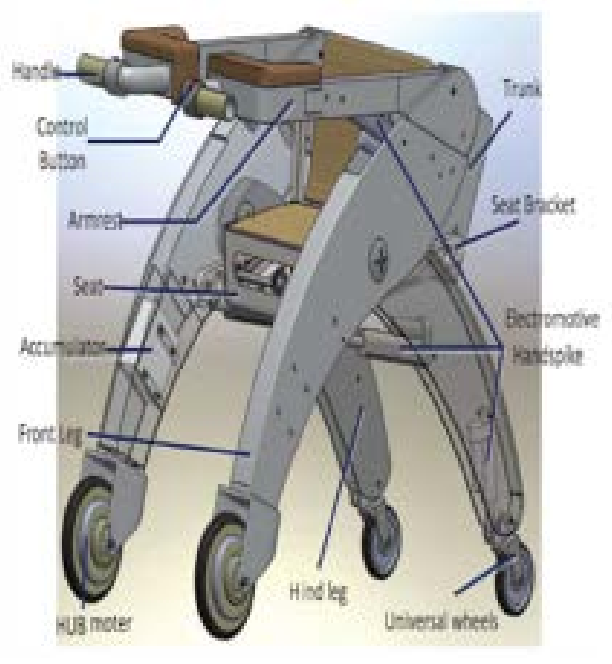

FIGURE I.OVERALL STRUCTURE OF EWR

System, Xi'an Jiaotong University. It is a multifunctional robot for both outdoor and indoor use under all conditions. It consists of many subsystems like a linear actuator which can change the robot's posture to adapt different operating modes. The front wheels (Hub Motors) are the driving wheels. The rear-wheels are the universal wheels. And the differential speeds between the two front wheels is used to control the direction of the EWR which will be the research task. The two front wheels are driven by the two 12V BLDC motor [2]. Tactile slip sensors (FSR) made from Polyvinylidene difluoride (PVDF) materials attached to the robot's handle to detect the force / pressure which conveys users intended motion speed and direction and sends the signal to the ATMega 16 micro controller [3].

Hall sensors or encoders on the BLDC motor detect the motor position and send the signal to the ATMega 16 microcontroller to process it and correct the error.

\section{A. Tactile Slip Sensor \\ Force Sensitive Resistor Round 0.5}


The 0.5 " force sensitive resistor (FSR) is a quick way to measure pressure, and is very easy to setup. The FSR varies its resistance depending on how much pressure is applied to the sensing area. The greater the force, the lower the resistance [3]. When measured with a multimeter, the sensor has a resistance of greater than $1 \mathrm{M} \Omega$ when no pressure is applied. FSR mounted on the the robot's handle to detect the force /

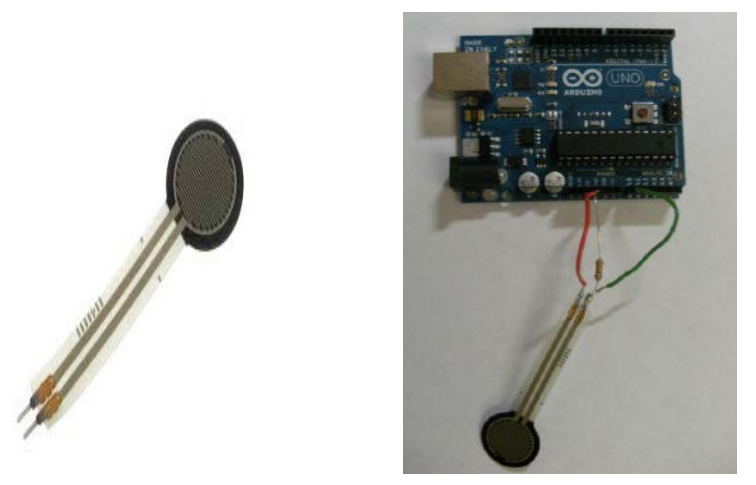

FIGURE II.

FORCE SENSITIVE RESISTANCE (FSR)

Pressure which conveys users intended motion, speed and direction.

\section{B. Microcontroller}

Arduino ATMega 16

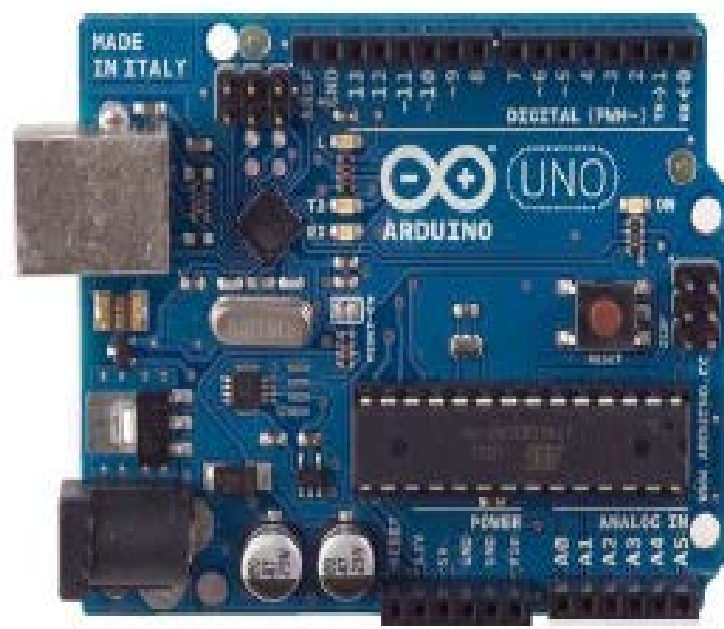

FIGURE III.

ATMEGA 16 MICROCONTROLLER

The Arduino microcontroller is an easy to use yet powerful single board computer that has gained considerable traction in the hobby and professional market. Arduino ATMega16 used in this research is shown in Figure 3. The Arduino is opensource, which means hardware is reasonably priced and development software is free. Microcontroller uses PID algorithm to generate PWM pulses for regulation of BLDC motor [4].

C. Motor Driver

ZD-6718 V3
Controller generates 5V PWM and is applied at the input of the driver circuit. Because of PWM driver circuits gives pulses of $12 \mathrm{~V}$ DC voltage to regulate power at the terminals of BLDC motor. In this paper, ZD-6718 V3 high performance BLDC motor driver is used as motor driver [5]. As shown in Figure.4. This motor driver is a three-phase full-bridge, PWM mode

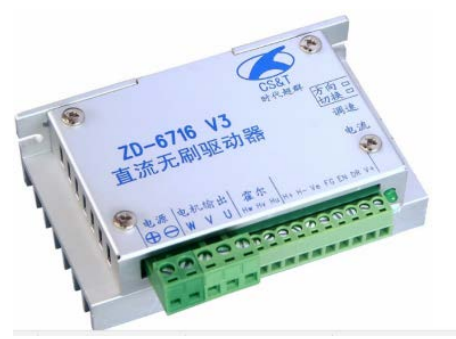

FIGURE IV.

BLDC MOTOR DRIVER (ZD-6718 V3)

closed loop speed and large driver in which all the control and output interfaces are optoelectrically isolated.

\section{Bldc Motor}

\section{Maxon BLDC Motor}

The BLDC motor used for the EWR has $12 \mathrm{~V}$ and 2860RPM voltage and speed ratings respectively as shown in Figure 5. The BLDC motor has built in load torque capability. The speed of BLDC motor is controlled by PID [6]. The BLDC motor has embedded hall sensors.

\section{E. Hall Sensors}

Encoder is used to measure the real speed of motor and converts it into a form compatible to microcontroller. This information is given back to the controller for the estimation of control signal to generate accurate PWM to drive the motor at desired speed [7]. The BLDC motor used has built in encoder to measure speed. This encoders are shown in Figure 5.

\section{System Mathematical Model}

A schematic diagram of a BLDC motor is shown in Figure.6, along with its equivalent circuit in Figure.7.

Typically, the mathematical model of a BLDC motor is not totally different from the conventional DC motor. The major addition is the phases involved which affects the overall results of the BLDC model [6]. The phases peculiarly affect the resistive and inductive of the BLDC arrangement. The threephase BLDC motor is controlled by the full bridge driving in the two phase conduction mode.

The three phase star connected BLDC motor can be described by the following equations: 

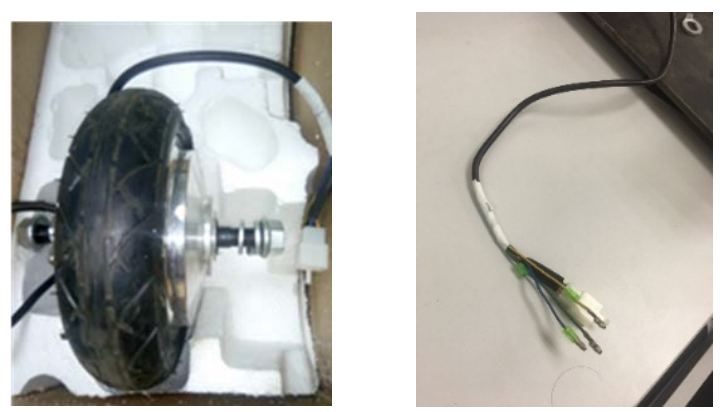

FIGURE V.

BLDC MOTOR WITH HALL SENSORS

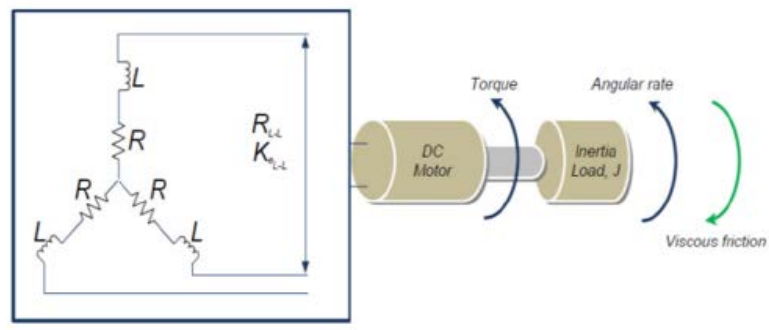

FIGURE VI.

SCHEMATIC OF BLDC MOTOR

$v_{a b}=R\left(i_{a}-i_{b}\right)+L \frac{d}{d t}\left(i_{a}-i_{b}\right)+e_{a}-e_{b}$

$v_{b c}=R\left(i_{b}-i_{c}\right)+L \frac{d}{d t}\left(i_{b}-i_{c}\right)+e_{b}-e_{c}$

$$
v_{c a}=R\left(i_{c}-i_{a}\right)+L \frac{d}{d t}\left(i_{c}-i_{a}\right)+e_{c}-e_{a}
$$
as:

The back-emf's and the electrical torque can be expressed

$$
\begin{array}{r}
e_{a}=\frac{k_{e}}{2} \omega_{m} F\left(\theta_{e}\right) \\
e_{b}=\frac{k_{e}}{2} \omega_{m} F\left(\theta_{e}-\frac{2 \pi}{3}\right) \\
e_{c}=\frac{k_{e}}{2} \omega_{m} F\left(\theta_{e}-\frac{4 \pi}{3}\right)
\end{array}
$$

$$
T_{e}=\frac{k_{t}}{2}\left[F\left(\theta_{e}\right) i_{a}+F\left(\theta_{e}-\frac{2 \pi}{3}\right) i_{b}+F\left(\theta_{e}-\frac{4 \pi}{3}\right) i_{c}\right]
$$

The mathematical models in state-space representation and the complete model is then:

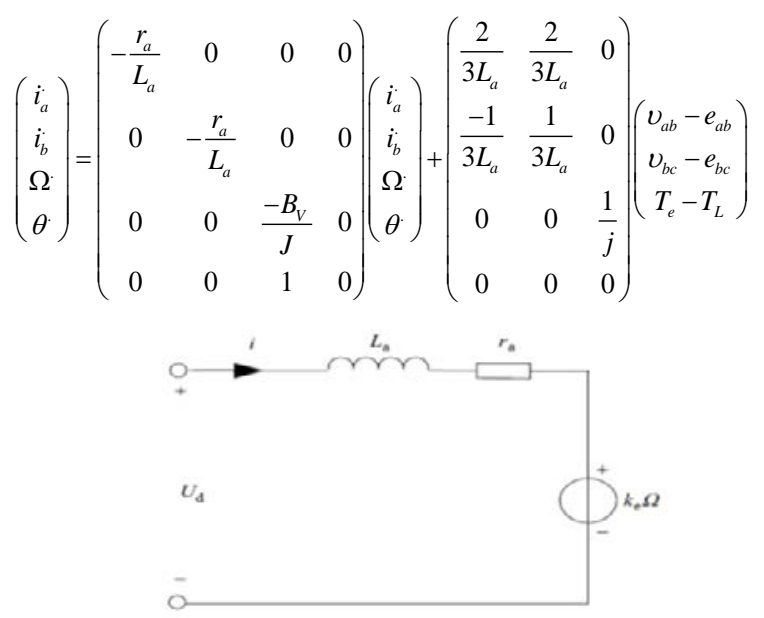

FIGURE VII. EQUIVALENT CIRCUIT OF THE BLDC MOTOR

Where $\theta=$ rotor position

$$
\begin{aligned}
& v_{a b} v_{b c}=\text { Line voltage } \\
& e_{a b} e_{b c}=\text { Line back emf } \\
& r_{a}=\text { Phase resistance of winding }=2 \mathrm{R}
\end{aligned}
$$

$\mathrm{J}=$ rotor moment of inertia

$\mathrm{T}_{\mathrm{L}}=$ load torque

$\mathrm{B}_{\mathrm{V}}=$ viscous friction coefficient

$\mathrm{I}_{\mathrm{a}} \mathrm{I}_{\mathrm{b}}=$ phase current

\section{CONTROL ARCHITECTURE FOR ELDERLY \& WALKING ASSISTANT ROBOT}

The designed control architecture for the EWR is shown in Figure 8. The transfer function of the PID controller is $K(s)=K_{P}+\frac{K_{I}}{s}+K_{D} s$

where $K_{P}, K_{I}$ and $K_{D}$ are proportional, integral and differential gains respectively. The function of each part of a PID controller can be described as follows, the proportional part reduces the error responses of the system to disturbances, the integral part eliminates the steady -state error and finally the derivative part dampens the dynamic response and improves the system stability [8]. The problem in the PID controller is to choose the three parameters to be suitable for the controlled plant. There are many methods to define the parameters of PID controller such as trial and error and Ziegler 
- Nichols methods but most of this methods are rough roads [9]. In this paper, the parameter of PID controller obtained by Ziegler-Nichols method is used.

\section{F. Specification of Bldc Motor}

Maxon BLDC motor was used with the specification as shown in Table1.

The equation of the BLDC motor is

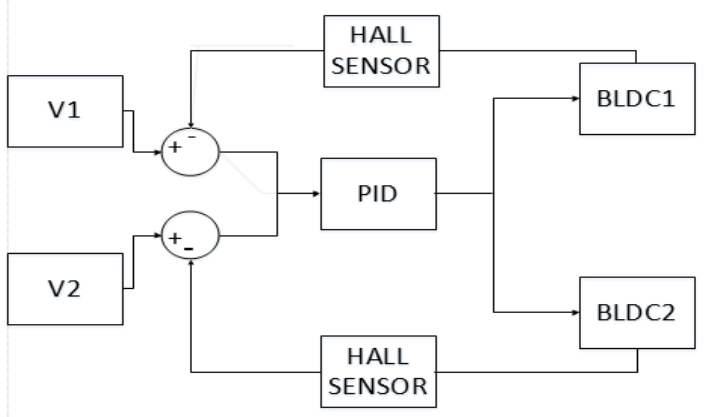

FIGURE VIII

CONTROL SYSTEM ARCHITECTURE

$$
\begin{gathered}
G(s)=\frac{\frac{1}{K_{e}}}{\tau_{m} \tau_{e} s^{2}+\tau_{m} s+1} \\
K_{e}=0.0763 \mathrm{vsec} / \mathrm{rad} \\
\tau_{m}=0.0171 \mathrm{sec} \\
\tau_{e}=155.56 \times 10^{-6} \mathrm{sec} \\
G(s)=\frac{13.11}{155.56 \times 10^{-6} \mathrm{~s}^{2}+0.0171 \mathrm{~s}+1}
\end{gathered}
$$

Where $K_{e}=$ electrical torque

$$
G(s)=\text { BLDC transfer function }
$$

$\tau_{m=\text { mechanical time constant }}$

$\tau_{e=\text { electrical time constant }}$
TABLE I. SPECIFICATION OF THE MAXON BLDC MOTOR

\begin{tabular}{|l|l|c|c|}
\hline \multirow{2}{*}{$\begin{array}{c}\text { Table } \\
\text { Head }\end{array}$} & \multicolumn{1}{|c|}{ Table Column Head } \\
\cline { 2 - 4 } copy & Values at nominal voltage & Unit & Value \\
\hline 1 & Nominal Voltage & $\mathrm{V}$ & 12.0 \\
\hline 2 & No load Speed & $\mathrm{rpm}$ & 4370 \\
\hline 3 & No load Current & $\mathrm{mA}$ & 151 \\
\hline 4 & Nominal Speed & $\mathrm{rpm}$ & 2860 \\
\hline 5 & $\begin{array}{l}\text { Nominal Torque (maximum } \\
\text { continuous torque) }\end{array}$ & $\mathrm{mNm}$ & 59.0 \\
\hline 6 & $\begin{array}{l}\text { Nominal Current (maximum } \\
\text { continuous current) }\end{array}$ & $\mathrm{A}$ & 2.14 \\
\hline 7 & Stall Torque & $\mathrm{mNm}$ & 255 \\
\hline 8 & Starting Current & $\mathrm{A}$ & 10.0 \\
\hline 9 & Maximum Efficiency & $\%$ & 77 \\
\hline 10 & $\begin{array}{l}\text { Terminal Resistance phase to } \\
\text { phase }\end{array}$ & ' & 1.20 \\
\hline 11 & $\begin{array}{l}\text { Terminal Inductance phase to } \\
\text { phase }\end{array}$ & $\mathrm{mH}$ & 0.560 \\
\hline 12 & Torque Constant & $\mathrm{mNm} / \mathrm{A}$ & 25.5 \\
\hline 13 & Speed Constant & $\mathrm{rpm} / \mathrm{V}$ & 37.4 \\
\hline 14 & Speed Torque Gradient & $\mathrm{rpm} / \mathrm{mNm}$ & 17.6 \\
\hline 15 & Mechanical Time Constant & 92.5 \\
\hline 16 & Rotor Inertia & 3.1 \\
\hline 17 & Number Of Phases & & 3 \\
\hline
\end{tabular}

G. Matlab/Simulink Model of the Pid Controller

The model of the PID Controller in SIMULINK is shown in Figure 9.

Two inputs from the FSR mounted on both handles of the EWR are used to send inputs to the single PID controller which controls the two BLDC motors. The various EWR controller functions are:

Turn left $\quad \mathrm{V} 1>\mathrm{V} 2$

Turn right $\mathrm{V} 1<\mathrm{V} 2$

Move straight-forward V1=V2

Move Backward $-\mathrm{V} 1=-\mathrm{V} 2$

Move slowly in circular direction. Either of V1 or V2=+; or $\mathrm{V} 2=0$

Move Fast in circular direction $\mathrm{V} 1=-\mathrm{V} 2$

Stop. V1=V2=0

\section{H. Tuning the Pid Controller}

There are two methods for determination of the parameters of PID controllers called Ziegler-Nichols tuning rules. But the widely accepted method for tuning the PID controller is straightforward method. First set the controller to P mode only. Next set the gain of the controller $\left(K_{P}\right)$ to a small value. If $K_{P}$ is 
low, the response of the system should be sluggish, increase $K_{P}$ by a factor of two and keep increasing $\mathrm{K}_{\mathrm{P}}$ (by a factor of two) until the response of the system becomes oscillatory. Finally, adjust $K_{P}$ until a response is obtained that produces continuous oscillations [9] .This is known as the ultimate gain $(\mathrm{Ku})$ or. Note that the period of the oscillation is known as the ultimate period $(\mathrm{Tu})$.

The steps required for the method are given below;

The integral and derivative coefficients have to set (gains) to zero.

Gradually increase the proportional coefficient from zero to until the system just begins to oscillate continuously (sustained oscillation) [10]. The proportional coefficient at this point is called ultimate gain $(\mathrm{Ku})$.

And the period of oscillation at this point is called ultimate period (Tu) [11].

The Ziegler-Nichols tuning rules are then obtained from Table 2.

It was found that the critical gain $\mathrm{Ku}=84$ and the critical period $\mathrm{Tu}=0.15 \mathrm{sec}$ and the PID controller is shown in Figure 9, where $\mathrm{K}_{\mathrm{P}}=49.41, \mathrm{~K}_{\mathrm{I}}=0.075$ and $\mathrm{K}_{\mathrm{D}}=0.01875$

\section{TABLE II.TUNED CONTROLLER PARAMETER}

\begin{tabular}{|l|l|c|c|}
\hline $\begin{array}{l}\text { Controller } \\
\text { Type }\end{array}$ & $\mathrm{K}_{\mathrm{P}}$ & $\mathrm{K}_{\mathrm{I}}$ & $\mathrm{K}_{\mathrm{D}}$ \\
\hline $\mathrm{PID}$ & $\mathrm{Ku} / 1.7$ & $\mathrm{Tu} / 2$ & $\mathrm{Tu} / 8$ \\
\hline
\end{tabular}

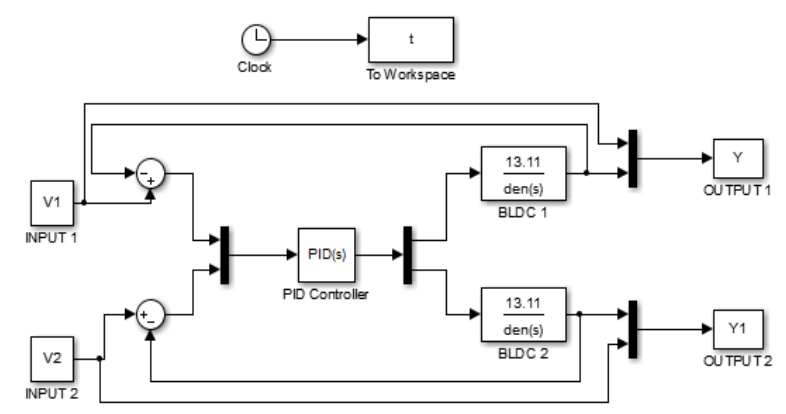

FIGURE IX. SIMULINK MODEL OF EWR CONTROL SYSTEM

\section{V.RESULTS}

The simulation results of speed and direction control of BLDC motor are presented in Figure 10 to Figure 13.

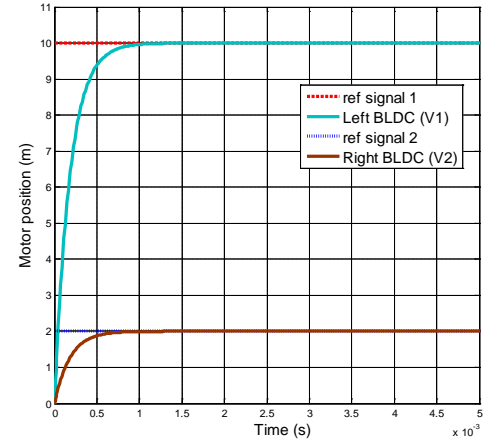

FIGURE X. $\quad$ V1>V2 EWR TURNS RIGHT

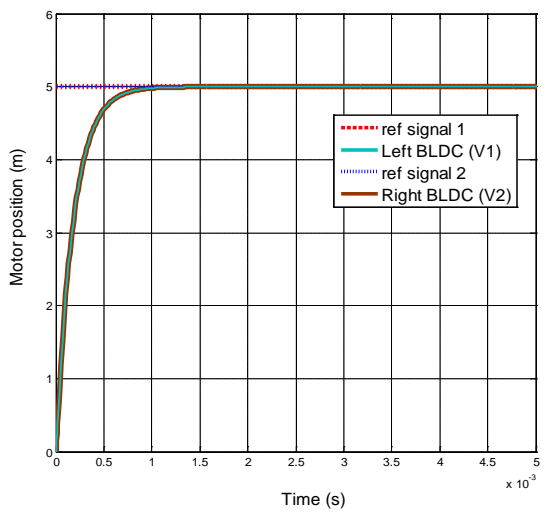

FIGURE XI. V1=V2 EWR MOVES STRAIGHT FORWARD

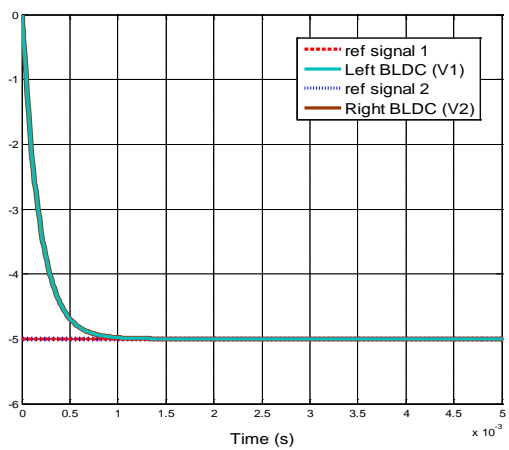

FIGURE XII. $\quad-$ V1 $=-$ V2 EWR MOVES STRAIGHT BACKWARD

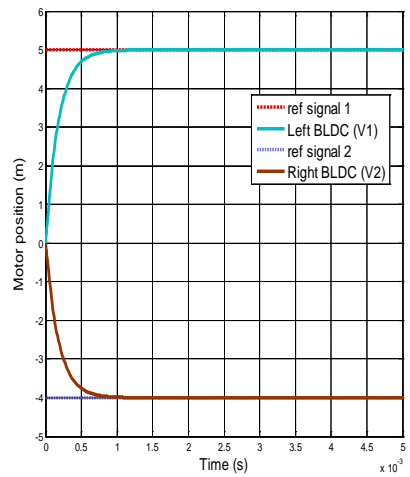

FIGURE XIII. 
From Figure 10 to 13, it can be seen that the speed differential in both BLDC motors determines the direction of robot motion.

\section{CONCLUSION}

For controlling the speed and direction of an elderlyassistant and walking-assistant robot (EWR) by controlling the speed and direction of two 12V brushless DC (BLDC) motor driving two front hub wheel of the EWR, a PID controller was successfully investigated and applied. The result of the experiment on the real plant demonstrates that the PID controller is a good choice to suppress the oscillation due to the systems and sensors nonlinearity.

\section{ACKNOWLEDGMENT}

The authors are grateful for the support provided by the science and technology innovation project of Shaanxi province, China (2015KTZDGY-02-01).

\section{REFERENCES}

[1] Khaled Silan, Prof. Dr -Lng Klaus-Dieter Kuhnert: DC Motor Angular position control using PID Controller for the purpose of controlling the hydraulic pump. International Conference on control, Engineering \& Information Technology (CEIT'13) proceedings Engineering and Technology.-vol. 1,pp22, 26, 2013.

[2] Zhifa Lai, Xiaodong Zhang, Gui Yin: Research on Key Technology of Multifunctional Elderly-assistant and Walking-assistant Robot. International Conference on Ubiquitous Robots and Ambient Intelligence (URAI), August 2016.

[3] Claudio Melchorii: Slip Detection and Control using Tactile and Force Sensor. IEEE/ASME Transactions on Mechatronics, vol,5, No. 3, September 2013.

[4] W. Durfee: Arduino Microcontroller Guide oct. 2011 University of Minnesota.http://www.arduino.cc/.

[5] Shrivastava S., Rawat J., Agarwal A.: Controlling DC Motor using Microcontroller (PIC16F72) with PWM. International Journal of Engineering Research, 1, 2012, 45-47.

[6] G SantoshKumar, S. Arockia Edwin Xavier: Brushless DC motor control using microcontroller. Thiagarajar College of Engineering, Electrical and Electronic Engineering, Madurai, Tamil Nadu.

[7] Oludayo John Oguntoyinbo: PID Control of Brushless DC motor and Robot Trajectory Planning and Simulation with MATLAB/SIMULINK. Yrkeshogskola University of Applied Science.

[8] Bhagat N.A., Bhaganara M.: DC Motor Speed Control using PID Controllers, Electronic System Design Course Project. University of IIT Bombay, 2009.

[9] Kamar U., Narvey R.: Speed Control of DC Motor Using Fuzzy PID Controller. Advance in Electronic and Electric Engineering, 3, 2013, 1209-1220.

[10] Saridhar N., Ramrao N., Singh M.K.: PID Controller Auto Tuning using ASBO Technique. Journal of Control Engineering and Technology, 4, 2014, 192-204.

[11] Das S., Pan I., Halder K., Das S., Gupta A.: LQR based improved discrete PID controller design via optimum selection of weighting matrices using fractional order integral performance index. Applied Mathematical Modeling, 37, 2013, 4253-4268. 